\title{
Commentary: Subpulmonary pump in Fontan circulation: Can it be a breakthrough in treatment of the single ventricle?
}

\author{
Katsuhide Maeda, MD, PhD
}

\author{
From the Department of Cardiothoracic Surgery, Stanford University School of Medicine, Stanford, Calif. \\ Disclosures: Author has nothing to disclose with regard to commercial support. \\ Received for publication July 10, 2019; revisions received July 11, 2019; accepted for publication July 15, 2019; \\ available ahead of print Aug 20, 2019. \\ Address for reprints: Katsuhide Maeda, MD, PhD, Department of Cardiothoracic Surgery, Stanford University, \\ 300 Pasteur Dr, Stanford, CA 94305 (E-mail: kmaeda@stanford.edu). \\ J Thorac Cardiovasc Surg 2019;158:1641-2 \\ 0022-5223/\$36.00 \\ Copyright (C) 2019 by The American Association for Thoracic Surgery \\ https://doi.org/10.1016/j.jtcvs.2019.07.047
}

It has been almost half a century since the first successful report of Fontan surgery. ${ }^{1}$ Without any doubt, this was one of the major breakthroughs in the history of cardiac surgery and brought a ray of light to a previously unrepairable and lethal heart condition. However, long-term survival after the Fontan operation is still far from satisfactory. ${ }^{2}$ Efforts to improve survival to date have focused on optimization of the design of the Fontan circuit per se to make the best use of the single energy source from the single ventricle. For instance, total cavopulmonary connection (TCPC), Y-graft Fontan, or optimal configuration of superior vena cava and inferior vena cava anastomosis have been extensively investigated and used. However, mechanical aspects of this surgery and remaining ventricle function protection have reached a plateau and little improvement can be foreseen in the near future.

It might now be time to think about a new strategy, that is, adding energy source from outside. The essence and the bottle neck of the Fontan circulation is the deficiency of energy, deriving from the patient's absent subpulmonary ventricle. The group of Rodefeld and colleagues has been studying the possibility of adding a long-term subpulmonary pump, to remedy this deficiency. ${ }^{3}$ This report, building upon the author's previous studies, shows the feasibility of a rotary blood pump on the basis of the von Karman viscous pump in the TCPC circuit. It raises the pressure by 6 to $8 \mathrm{~mm} \mathrm{Hg}$ easily, ranging up to $14 \mathrm{~mm} \mathrm{Hg}$. Its unique structure allows the pump to sit between vena cavae and pulmonary arteries at its junction and not only decrease central venous pressure but also increase the cardiac output. Moreover, in the event of pump stoppage, it does not cause any discernible pressure loss across the TCPC circuit.

Can this represent a breakthrough in single ventricle treatment? It seems promising. However, there remain multiple issues which need to be solved. Besides durability, hemolysis and thrombogenicity, desirable technical features

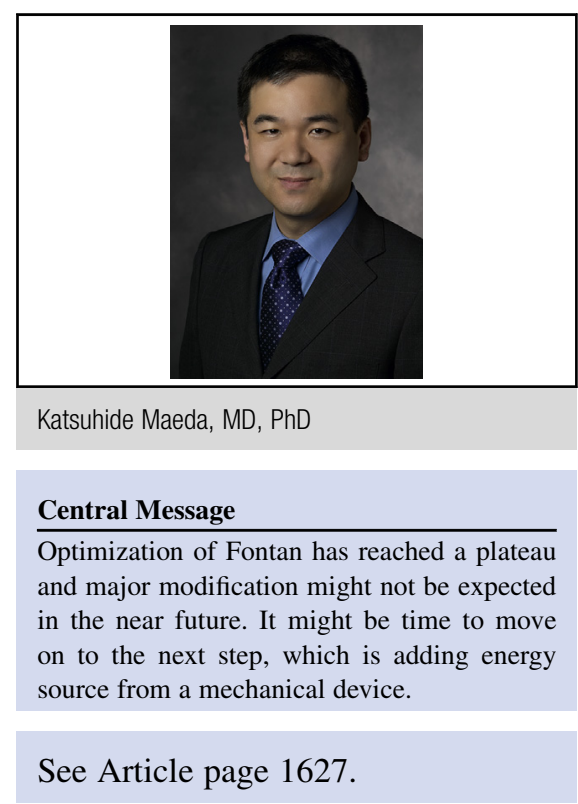

are well described in Table 1 in their report. The ideal device would be controlled wirelessly and battery-driven and would be easily replaceable like an implantable cardiac pacemaker. The road to the ideal device has just started and there is a long way to go.

In addition to technical features, the most important factor is the timing of placement of the device. The Fontan paradox starts as soon as Fontan surgery is performed. Obviously, it is too late to intervene when end organ damage has happened. It would be ideal to intervene well before end organs get insulted. Equally importantly, Fontan circulation is not the only type of single ventricular physiology, which relies on a single ventricle. Even in the first stage with pulmonary shunt or band, or the second stage with bidirectional Glenn, the fact that a patient relies on a single energy source holds true. Even well before Fontan, a patient might require an energy source from the outside.

It is stated by Fontan himself that, "The inference is that the premature decline in survival and functional status and the late rise in hazard function are from the Fontan state per se and that the Fontan operation is, therefore, palliative but not curative." 5 It is a bridge to the next. We hope "the next" is coming soon for patients who long for good quality of life with a single ventricle. 


\section{References}

1. Fontan F, Baudet E. Surgical repair of tricuspid atresia. Thorax. 1971;26:240-8. 2. Schilling C, Dalziel K, Nunn R, Du Plessis K, Shi WY, Celermajer D, et al. The Fontan epidemic: population projections from the Australia and New Zealand Fontan Registry. Int J Cardiol. 2016;219:14-9.

3. Rodefeld M, Marsden A, Figliola R, Jonas T, Nerary M, et al. Cavopulmonary assist: long-term reversal of the Fontan Paradox. J Thorac Cardiovasc Surg. 2019;158: 1627-36.
4. Honjo O, Merklinger SL, Poe JB, Guerguerian AM, Zhang H, Taylor KL, et al. Mechanically assisted bidirectional Cavo pulmonary shunt in neonates and infants: acute human pilot study. J Thorac Cardiovasc Surg. 2017;153:441-7.

5. Fontan F, Kirklin JW, Fernandez G, Costa F, Naftel DC, Tritto F, et al. Outcome after a "perfect" Fontan operation. Circulation. 1990;81: 1520-36. 